\title{
Melanoma Arising in Giant Congenital Nevus
}

National Cancer Institute

\section{Source}

National Cancer Institute. Melanoma Arising in Giant Congenital Nevus. NCI Thesaurus.

Code C4235.

A melanoma arising in a giant congenital melanocytic nevus. The risk of developing a melanoma in a giant congenital melanocytic nevus has been reported to be between 5\% and $50 \%$. The incidence of developing melanoma is higher before the age of 10 and in adult life. 